\title{
НЕНАНЕСЕНИЕ ЗНАЧИТЕЛЬНОГО УЩЕРБА В СИСТЕМЕ ПРИНЦИПОВ ИСПОЛЬЗОВАНИЯ И ОХРАНЫ РЕСУРСОВ ПРЕСНОЙ ВОДЫ
}

Аннотация. В статье рассматривается принцип ненанесения значительного ущерба другому государству при использовании трансграничных пресноводных объектов, его юридическое содержание, в частности, обязательства государств, понятие ущерба, его пределы, а также его соотношение с приниипами справедливого и разумного использования ресурсов пресной воды, предотвращчения загрязнения окружающей среды, принятия мер предосторожности, «загрязнитель платит», обязанность проводить оценку трансграничного воздействия. Автором проанализированы универсальные и региональные международные договоры, двусторонние соглашения России, в которых нашел закрепление указанный принцип. Особый упор сделан на освещцение отечественной и зарубежной доктрины относительно рассматриваемого принципа. Методологическую основу научного исследования составили системный анализ и синтез, аналогия, дедукиия, индукиия, абстрагирование, логический, сравнительно-правовой методы. В результате проведенного исследования установлено, что приниип ненанесения значительного ущерба равно включает как обязательство по предотвращению ущеерба, так и необходимость его уменьшения, ликвидации и компенсации, тем самым охватывает своим содержанием требования предотвращения загрязнения окружающей среды, принятия мер предосторожности, «загрязнитель платит», обязанность проводить оценку трансграничного воздействия. Под ущербом в рамках данного принципа следует понимать гибель или причинение вреда здоровью людей, утрату или повреждение имущества, ущерб окружающей среде, расходы на разумные меры по восстановлению прежнего состояния имущества или среды. Обоснована несостоятельность доктринальных противопоставлений и разграничений сфер применения рассматриваемого приниипа и справедливого и разумного использования ресурсов пресной воды.

Ключевые слова: Пресная вода, приниипы использования воды, ненанесение значительно ущерба, справедливое использование водотока, рациональное использование водотока, принции предотвращения вреда, принцип загрязнитель платит, оценка трансграничного воздействия, международный водоток, трансграничный водоносный горизонт.

Abstract: This article examines the principle of not causing significant damage to another country during the use of transboundary freshwater sources, its legal content, including the obligation of each state, concept of damage, its limitations, as well as its correlation with the principles of fair and reasonable use of freshwater resources, prevention of polluting the environment, implementation of safety measures, "polluter pays", and the responsibility to assess transboundary effects. The author analyzes the universal and regional international treaties, as well as bilateral agreements with Russia. As a result of the conducted research, the author determines that the principle of not causing significant damage includes in itself not only the obligation to prevent damage, but also containing the damage in the event that it has occurred, 
liquidating it, and compensating any damages. The damages should be understood as loss of life due to impact to human health, loss of or harm to property, damage to the environment, as well as expenses for reasonable measures of restoration to the previous state of property or the environment.

Keywords: Transboundary impact assessment, polluter pays principle, precautionary principle, reasonable utilization of the watercourse, equitable utilization of the watercourse, not to cause significant harm, principles of the use of water, freshwater, international watercourse, transboundary aquifer.

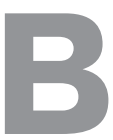
положениях практически всех международных договоров по вопросам использования и охраны трансграничных ресурсов пресной воды в качестве одного из руководящих начал закреплен принцип ненанесения значительного ущерба другому государству. Наличие данного принципа не подвергается сомнению и в доктринальных источниках по данной теме. Однако немало дискуссий вызывает определение содержания и места принципа ненанесения значительного ущерба в системе принципов использования и охраны ресурсов пресной воды.

Юридическое содержание рассматриваемого принципа заключается в обязательстве принять на своей территории все надлежащие меры для предотвращения значительного вреда другому государству посредством использования трансграничного пресноводного объекта и уменьшения или ликвидации такого вреда, а также его компенсации. Рассматривая содержание указанного принципа, следует акцентировать внимание на двух аспектах: а) уровень ущерба и б) необходимость принятия действий или предотвращения негативного результата.

Практически во всех универсальных и региональных международных договорах по вопросам использования и охраны ресурсов пресной воды уровень ущерба, причинение которого влечет ответственность государ- ства, определяется как «значительный»[1]. Аналогичный уровень ущерба установлен в двусторонних договорах Российской Федерации по водным ресурсам, формулировки которых в этой части, фактически, дублируют положения Конвенцию по охране и использованию трансграничных водотоков и международных озер 1992 г.[2]. Значительный ущерб раскрывается в ст. 1 Пересмотренного протокола по разделяемым системам водотоков 2000 г. как ущерб, не являющийся малым, обнаруживаемый на основе объективных доказательств и необязательно возросший до уровня существенного. Аналогичным образом понятие значительного ущерба раскрывается в комментариях КМП ООН к Проектам статей о предотвращении вреда от опасных видов деятельности 2001 г.[3], Проектам принципов, касающихся распределения убытков в случае трансграничного вреда, причиненного в результате опасных видов деятельности 2006 г.[4], Проектам статей по праву трансграничных водоносных горизонтов 2008 г. (далее - Проекты статей 2008 г.)[5] - значительный характер ущерба означает нечто большее, чем «поддающийся обнаружению», но не обязательно «серьезный» или «существенный»[6]. Установление подобного оценочного критерия является оправданным, т.к. позволяет определить порог для наступления ответственности государства в каждом конкретном случае 
на основе индивидуальных для данной ситуации естественных и антропогенных факторов.

Под ущербом в рамках рассматриваемого принципа следует понимать причиненный другому государству вред посредством использования воды или «резервуара» (дна реки, озера, канала, геологической породы водоносного горизонта) трансграничного пресноводного объекта, в частности, гибель или причинение вреда здоровью людей, утрату или повреждение имущества, ущерб окружающей среде, расходы на разумные меры по восстановлению прежнего состояния имущества или среды. Представляются необоснованными позиции отдельных ученых, согласно которым невключение положений о компенсации в Проекты статей 2008 г., влечет отсутствие необходимости возместить причиненный ущерб[7]. Обязательство компенсировать причиненный ущерб проистекает из характера правоотношений, складывающихся в результате его причинения. Нанесение ущерба другому государству представляет собой международно-противоправное деяние государства, соответственно вопрос о компенсации урегулирован действующими нормами международного права об ответственности государств, согласно которым ответственное государство обязано предоставить полное возмещение вреда[8].

Неоправданным является критика A.Е. Юттона (США) принципа ненанесения значительного ущерба как не включающего ущерб окружающей среде и экосистемам других государств[9]. Во-первых, данный принцип касается случаев причинения ущерба другому государству через международный водоток или трансграничный водоносный горизонт; последние при этом сами являются экосистемами или частями других, больших экосистем. Таким образом, представляется невозможным причинение вреда другому государству посредством использования трансграничного пресноводного объекта, без причинения ущерба самому объекту. Более того, Конвенция о праве несудоходных видов использования международных водотоков 1997 г. (далее - Конвенция 1997 г.)[10], Проекты статей 1994 г.[11] и 2008 г. включают отдельные положения о защите и сохранении экосистем, конкретизирующие содержание рассматриваемого принципа. Во-вторых, сложившееся в настоящее время понимание ущерба, включает любой моральный и материальный вред, т.е. в том числе ущерб окружающей среде и расходы на меры по ее восстановлению[12].

Важным аспектом при рассмотрении содержания принципа ненанесения значительного ущерба является вопрос о том, охватывает ли данный принцип негативный результат или касается лишь поведения государства. В доктрине международного права широко распространено мнение, что рассматриваемый принцип сводится лишь к стандарту должной осмотрительности, поведению субъекта, нежели к абсолютному обязательству относительно результата[12]. На наш взгляд, подобный подход является не совсем верным. Как уже отмечалось, принцип ненанесения значительного ущерба налагает обязательства по принятию всех надлежащих мер для предотвращения значительного вреда другому государству, а также для его уменьшения или ликвидации, и компенсации за него. Обязательство принять все надлежащие меры, в частности, включает создание необходимой нормативной базы, введение ее в действие, предотвращение или приостановление незаконной деятельности, наказание ответственных 
лиц, иные технические и финансовые действия. Само по себе непринятие указанных мер без факта причинения вреда другому государству не способно породить материальную ответственность государства и поставить вопрос о компенсации; обязанность возместить причиненный ущерб возникает у государства лишь в случае его реального наличия. Таким образом, для реализации рассматриваемого принципа важны как превентивные действия государства, так и их результат.

В международно-правовой доктрине высказываются различные точки зрения относительно места принципа ненанесения значительного ущерба в системе принципов использования и охраны ресурсов пресной воды. Так, К. Мешлем (Великобритания) пишет, что значительным вызовом в работе КМП над Проектами статей 2008 г. являлось определение взаимосвязи принципов справедливого и разумного использования и ненанесения значительного ущерба. При этом, исходя из системного анализа ст.ст. 4, 5 и 6 Проектов 2008 г., ученый приходит к выводу о приоритете принципа справедливого и разумного использования над ненанесением значительного ущерба, т.к. при использовании может быть причинен определенный вред[14]. Подобную позицию также поддерживает Р. Пейсли (Канада), аргументируя это тем, что в деле ГабчиковоНадьмарош Международный Суд ООН отклонил ссылку Словакии на принцип ненанесения значительного ущерба, тем самым подтвердив главенствующую роль принципа справедливого использования[15].

Иной точки зрения придерживается, П. Воутерс (Великобритания), которая в результате анализа Проектов статей 1994 г. и Хельсинских правил 1966 г., приходит к выводу, что принцип ненанесения значи- тельного ущерба является доминирующим в международном водном праве[16]. О. МакИнтаир (Великобритания) полагает, что все остальные принципы в определенной степени потеряют свой смысл без принципа ненанесения значительного ущерба[17]. По мнению С.А. Мохаммеда (Египет), проблемы использования водных ресурсов рек привели к возникновению принципа ненанесения значительного ущерба и, как следствие, справедливого и разумного использования[18].

Противопоставление принципов справедливого и разумного использования трансграничного пресноводного объекта и ненанесения ущерба другому государству, a также выгода первого из них для государств, расположенных выше по течению, а второго - для нижележащих государств отмечается в исследованиях А.Е. Юттона[19], М. Эрдема (Турция)[20], Н. Джайхана и Н. Попаттаначая (Таиланд)[21] и др.

Согласиться с подобным подходом к определению взаимосвязи указанных принципов не представляется возможным. Противопоставление или попытки установить иерархию принципов справедливого и разумного использования трансграничного пресноводного объекта и ненанесения значительного ущерба другому государству в корне неверны и не находят нормативного подкрепления. Оба принципа тесно связаны, совместно регулируют отношения по использования и охране ресурсов пресной воды и преследуют единые цели - обеспечение равенства государств при использовании вод, максимизацию благ от использования при минимизации экологических, экономических и иных потерь.

Отдельные исследователи предлагают следующее разграничение сферы действия указанных принципов: государства должны 
руководствоваться принципом справедливого и разумного использования относительно вопросов количества воды, а принципом ненанесения значительного ущерба - качества воды[22]. Схожая логика прослеживается в предложении С.Д. Махкамбаева, согласно которому принцип «загрязнитель платит» должно трансформироваться в «государство, превысившее лимит водозабора, должно платить»[23]. Во-первых, следует сразу оговориться, что в большинстве случаев далеко нелегко разграничить вопросы количества от вопросов качества воды. Во-вторых, значительный ущерб может быть причинен не только ухудшением качества воды путем загрязнения, привнесения чужеродных организмов и т.д., но также путем чрезмерного водозабора[24]. В частности, именно чрезмерный водозабор во многих регионах мира вызвал состояния «водного стресса» и «водного кризиса», характеризующиеся деградацией водных экосистем, засолением пресноводных объектов и т.д. Государство должно предпринять все надлежащие меры для предотвращения причинения ущерба, в частности, рассмотреть возможность удовлетворения потребностей за счет альтернативных источников воды. Использование геологической породы в качестве полезного ископаемого также способно существенно изменить распределение воды в трансграничном водоносном горизонте, что может повлечь причинение ущерба другому государству. В свою очередь, принцип справедливого и разумного использования не исчерпывается вопросами количества воды. Справедливость использования предполагает распределение не только воды, но и благ от ее использования, а также от использования «резервуара». Разумность заключается в принятии мер по максимизации благ при устойчивости трансграничного пресново- дного объекта, таким образом, ухудшение качества воды способно привести к уменьшению благ, а соответственно нарушению разумности использования.

В связи с рассмотрением вопроса о месте принципа ненанесения значительного ущерба в системе принципов использования и охраны ресурсов пресной воды следует также обратиться к его соотношению с такими принципами, как предотвращения загрязнения окружающей среды, принятия мер предосторожности, «загрязнитель платит», обязанность проводить оценку трансграничного воздействия.

Несмотря на то, что указанные принципы в исследованиях, посвященных международно-правовой охране окружающей среды, выделяются в качестве самостоятельных начал[25], на наш взгляд, в контексте использования и охраны ресурсов пресной воды они охватываются содержанием принципа ненанесения значительного ущерба. Как было указано выше, понятие ущерба в рамках принципа ненанесения значительного ущерба шире понятия загрязнение и включает также негативные последствия использования «резервуара», привнесения чужеродных видов, истощение вод и деградацию экосистемы трансграничного пресноводного объекта в результате чрезмерного водозабора и т.д. При этом на государства, разделяющие водный объект, возлагается обязательство не только по уменьшению или ликвидации ущерба и возмещению компенсации за него, но, в первую очередь, обязанность предпринять все надлежащие меры для предотвращения нанесения значительного ущерба. Таким образом, принятие всех надлежащих мер для предотвращения ущерба другому государству, разделяющему трансграничный пресноводный объект, охватывает меры по предотвращению за- 
грязнения окружающей среды и иные меры предосторожности. Кроме того, представляется затруднительным принятие мер по предотвращению значительного ущерба без проведения оценки трансграничного воздействия. В случае же нанесения ущерба, государство обязано возместить причиненный вред, что, как отмечалось выше, вытекает из существа возникающих в подобной ситуации правоохранительных отношений.

Подобная точка зрения находит подтверждение в положениях международных договоров по использованию и охране ресурсов пресной воды[26], а также в доктринальных источниках. В частности, положения частей III и IV Конвенции 1997 г. предусматривают необходимость уведомления о планируемых мерах, чреватых неблагоприятными последствиями, консультации и переговоры по ним, защиту и сохранение экосистем, предотвращение, сокращение и сохранение под контролем загрязнения и др. Аналогичные положения содержатся в части 3 Проектов статей 2008 г.

Пересмотренный протокол по разделяемым системам водотоков 2000 г, основанный преимущественно на положениях Конвенции 1997 г., в ст. 4 устанавливает обязанность уведомлять другое государство о планируемых мерах и проводить консультации и переговоры по ним. Такое уведомление должно быть своевременным, т.е. иметь место до начала осуществления деятельности, а также содержать доступные технические данные и информацию, включая результаты оценки воздействия на окружающую среду (далее - ОВОС). Часть 2 ст. 4 Пересмотренного протокола 2000 г., касающаяся защиты и сохранения окружающей среды, базируется на предосторожном подходе, предписывая предотвращать, сокращать и сохранять под контролем загрязнение и экологическую деградацию водотоков, способные причинить значительный ущерб окружающей среде, жизни и здоровью людей, водным и живым ресурсам водотока.

Обязанность проводить ОВОС планируемой деятельности, способной оказать негативное воздействие на трансграничный водный объект, и при необходимости экологическую экспертизу такой оценки, возместить причиненный ущерб, регулярный обмен данными и информацией о состоянии водных объектов устанавливается также в двусторонних соглашениях Российской Федерации по рациональному использованию водных ресурсов[27].

По справедливому мнению Д.А. Капонера (Италия), согласно принципу ненанесения значительного вреда государства должны принять адекватную нормативную базу для регулирования и контроля трансграничного загрязнения в пределах их юрисдикции с учетом технических и социально-экономических возможностей, а также обязаны развивать технологии для повторного использования и очистки вод[28].

П. Бирни (Нидерланды) и А. Бойл (Великобритания) верно отмечают правоту специального докладчика ООН в том, что принцип предосторожного подхода, оценка воздействия на окружающую среду включены в принцип ненанесения значительного вреда и не могут быть отделены от него. По мнению ученых, без проведения ОВОС обязательства по уведомлению и проведению консультаций и переговоров будут лишены всякого смысла[29].

Ф. Окова (Великобритания) полагает, что хотя Конвенция 1997 г. не включает обязательство по проведению оценки воздействия на окружающую среду, оно вытекает из других норм, в частности, из требований об 
уведомлении другого государства о предполагаемой деятельности, которая может причинить трансграничный ущерб[30].

Настоящая работа предпринята в связи с имеющимися в юридической литературе разногласиями относительно принципа ненанесения значительного вреда другому государству и направлена на установление юридического содержания и места указанного принципа в системе основных начал использования и охраны ресурсов пресной воды. В результате исследования автор пришел к следующим выводам.

Принцип ненанесения значительного ущерба налагает на государство обязательства по принятию на своей территории все надлежащих мер для предотвращения значительного вреда другому государству посредством использования трансграничного пресноводного объекта, уменьшению или ликвидацию его последствий, а также компенсации за него, тем самым охватывая требования предотвращения загрязнения окружающей среды, принятия мер предосто- рожности, «загрязнитель платит», обязанность проводить оценку трансграничного воздействия.

Рассматриваемый принцип предопределяет не только стандарт должного поведения государства и юридические последствия за его нарушение, но и ответственность за негативный результат ненадлежащего использования и охраны трансграничного пресноводного объекта.

Необоснованными являются доктринальные противопоставления, установления приоритета или разграничения сфер действия принципов ненанесения значительного ущерба другому государству и справедливого и разумного использования ресурсов пресной воды. Указанные принципы гармонично дополняют друг друга и, в конечном счете, направлены на достижение единых целей - установление равенства государств при использовании ресурсов пресной воды, максимизацию благ от их использования и минимизацию экологических, экономических и иных потерь.

\section{Библиография:}

1. См. Конвенция о праве несудоходных видов использования международных водотоков от 21 мая 1997 г., Конвенция по охране и использованию трансграничных водотоков и международных озер от 17 марта 1992 г., Пересмотренный протокол по разделяемым системам водотоков 2000 г. к Договору о Сообществе развития Юга Африки от 1992 г. и др.

2. См. Соглашения о совместном использовании и охране трансграничных водных объектов между Правительством Российской Федерации и Правительством Республики Абхазия от 06.10.2011 г.; Правительством Республики Беларусь от 24.05.2002 г.; Правительством Республики Казахстан от 07.09.2010 г.; Правительством Монголии от 11.02.1995 г.

3. Доклад Комиссии международного права о работе ее пятьдесят третьей сессии: док. ООН А/56/10. Нью-Йорк: ООН, 2001. С. 406-409.

4. Доклад Комиссии международного права о работе ее пятьдесят восьмой сессии: док. ООН А/61/10. Нью-Йорк: ООН, 2006. С. 122-124.

5. Проекты статей по праву трансграничных водоносных горизонтов с комментариями // Доклад Комиссии международного права о работе ее шестидесятой сессии: док. ООН A/63/10. НьюЙорк: ООН, 2008. С. 18-85.

6. Доклад Комиссии международного права о работе ее шестидесятой сессии: док. ООН А/63/10. Нью-Йорк: ООН, 2008. С. 51. 
7. McIntyre O. International Water Resources Law and the International Law Commission Draft Articles on Transboundary Aquifers: A Missed Opportunity for Cross-Fertilisation? // International Community Law Review Vol. 13, 2011, P. 247.

8. См. Проекты статей об ответственности государств за международно-противоправные деяния с комментариями // Доклад Комиссии международного права о работе ее пятьдесят третьей сессии: док. ООН А/56/10. Нью-Йорк: ООН, 2001. С. 12-380.

9. Utton A.E. Which Rule Should Prevail in International Water Disputes: That of Reasonableness or That of No Harm? // Natural Resources Journal Vol. 36, 1996, P. 640.

10. Конвенция о праве несудоходных видов использования международных водотоков от 21 мая 1997 г. URL: http://www.un.org/ru/documents/decl_conv/conventions/watercrs.shtml (дата обращения: 01.07.2015 г.).

11. Draft Articles on The Law of the Non-Navigational Uses of International Watercourses // Yearbook of the International Law Commission. 1994. Vol. II. Part 2. pp. 89-135.

12. См. ст. 31 Проектов статей об ответственности государств 2001 г., ст. 2 Проектов статей о предотвращении вреда от опасных видов деятельности 2001 г., Принцип 2 Проектов принципов о распределении убытков в случае трансграничного вреда от опасных видов деятельности 2006 г.

13. Yearbook of the International Law Commission. 1994. Vol. II. Part 2. P. 103. McIntyre O. The Role of Customary Rules and Principles of International Environmental Law in Protection of Shared International Freshwater Resources // Natural Resources Journal Vol. 46, 2006, P. 170. Traversi C. The Inadequacies of the 1997 Convention on International Water Courses and 2008 Draft Articles on the Law of Transboundary Aquifers // Houston Journal of International Law Vol. 33 No 2, 2011. pp. 482-484.

14. Mechlem K. Moving Ahead in Protecting Freshwater Resources: The International Law Commission's Draft Articles on Transboundary Aquifers // Leiden Journal of International Law Vol. 22, 2009, pp. 812-815.

15. Paisley R. Adversaries into partners: International Water Law and the equitable sharing of downstream benefits // Melbourne Journal of International Law Vol. 3, 2002, pp. 283-284.

16. Utton A.E. Op. Cit. P. 637.

17. McIntyre O. The Role of Customary Rules and Principles of International Environmental Law in Protection of Shared International Freshwater Resources. P. 171.

18. Mohamed S.A. Equitable and Reasonable Utilization of International Rivers in the UN Convention with a Particular Reference to the River Nile// African Perspectives Vol. 11 Issue 39, 2013, P. 23.

19. Utton A.E. Op. Cit. P. 635.

20. Erdem M. The Tigris-Euphrates rivers controversy and the role of International Law. P. 8. URL: http://sam.gov.tr/wp-content/uploads/2012/01/Mete-Erdem.pdf (дата обращения: 18.07.2015г.).

21. Jaihan N., Popattanachai N. Analysis of Thai Water Management Legislation from an International Law Perspective// Yonsei Law Journal Vol. 4 No. 2, 2013, pp. 353-354.

22. Grzybowski A., McCaffrey S., Paisley R. Beyond International water law: Successfully Negotiating Mutual Gains Agreements for International Watercourses // Global Business \& Development Law Journal Vol. 22, 2010, P. 142. McCaffrey S. An Assessment of the Work of the International Law Commission // Natural Resources Journal Vol. 36, 1996, P. 308. Utton A.E. Op. Cit. pp. 635-639.

23. Махкамбаев С.Д. Международно-правовое регулирование сотрудничества государств по использованию трансграничных водных ресурсов в регионе Центральной Азии: Дисс. ... канд. юрид. наук. М., 2011. С. 20.

24. Подобная ситуация наблюдаются на реках Тигр и Евфрат между Турцией, Ираком и Сирией, а также на реке Нил - между Египтом, Суданом и другими государствами, разделяющими реку. См. Erdem M. Op. Cit. Mekonnen D.Z. The Nile Basin cooperative framework agreement negotiations and the Adoption of a "Water Security Paradigm: Flight into Obscurity or a Logical Cul-de-Sac? // The European Journal of International Law Vol. 21 No. 2, pp. 421-440. Mohamed S.A. Op. Cit. 
25. Соколова Н.А. Теоретические проблемы международного права окружающей среды. Монография / Отв. ред.: Бекяшев К.А. - Иркутск: Изд-во Иркут. ун-та, 2002. С. 152. Тимошенко А.С. Формирование и развитие международного права окружающей среды / Отв. ред.: Колбасов O.C. - М.: Наука, 1986. С. 50-72. Nafziger J. Basic Functions and Principles of International Environmental Law in the Context of Managing Water Resources // Denver Journal of International Law and Policy Vol. 39 No. 3, 2011, pp. 381-395.

26. Следует оговориться, что в некоторых договорах по использованию и охране пресноводных ресурсов они разделяются. Например, Agreement on the Nile River Basin Cooperative Framework 2010. URL: http://www.internationalwaterlaw.org/documents/regionaldocs/Nile_River_Basin_ Cooperative_Framework_2010.pdf (дата обращения: 18.07.2015 г.).

27. Ст.ст.4-9 Соглашения с Правительством Республики Абхазия от 06.10.2011 г., ст.ст. 4-11 Соглашения с Правительством Республики Беларусь от 24.05.2002 г.; ст.ст. 3-11 Соглашения с Правительством Республики Казахстан от 07.09.2010 г.; ст.ст. 2-7 Соглашения с Правительством Монголии от 11.02.1995 г.

28. Caponera D.A. Patterns of Cooperation in International Water Law: Principles and Institutions. P. 570.

29. Birnie P., Boyle A. International Law and the Environment (second edition). Oxford University Press, 2002. P. 120.

30. Okowa Ph. Procedural Obligations in International Environmental Agreements // British Yearbook of International Law, 1996, P. 275-279

\section{References (transliterated):}

1. McIntyre O. International Water Resources Law and the International Law Commission Draft Articles on Transboundary Aquifers: A Missed Opportunity for Cross-Fertilisation? // International Community Law Review Vol. 13, 2011, P. 247.

2. Utton A.E. Which Rule Should Prevail in International Water Disputes: That of Reasonableness or That of No Harm? // Natural Resources Journal Vol. 36, 1996, P. 640.

3. Mechlem K. Moving Ahead in Protecting Freshwater Resources: The International Law Commission's Draft Articles on Transboundary Aquifers // Leiden Journal of International Law Vol. 22, 2009, pp. 812-815.

4. Paisley R. Adversaries into partners: International Water Law and the equitable sharing of downstream benefits // Melbourne Journal of International Law Vol. 3, 2002, pp. 283-284.

5. Utton A.E. Op. Cit. P. 637.

6. McIntyre O. The Role of Customary Rules and Principles of International Environmental Law in Protection of Shared International Freshwater Resources. P. 171.

7. Mohamed S.A. Equitable and Reasonable Utilization of International Rivers in the UN Convention with a Particular Reference to the River Nile // African Perspectives Vol. 11 Issue 39, 2013, P. 23.

8. Erdem M. The Tigris-Euphrates rivers controversy and the role of International Law. P. 8. URL: http://sam.gov.tr/wp-content/uploads/2012/01/Mete-Erdem.pdf (data obrashcheniya: 18.07.2015 g.).

9. Jaihan N., Popattanachai N. Analysis of Thai Water Management Legislation from an International Law Perspective// Yonsei Law Journal Vol. 4 No. 2, 2013, pp. 353-354.

10. Grzybowski A., McCaffrey S., Paisley R. Beyond International water law: Successfully Negotiating Mutual Gains Agreements for International Watercourses // Global Business \& Development Law Journal Vol. 22, 2010, P. 142. McCaffrey S. An Assessment of the Work of the International Law Commission // Natural Resources Journal Vol. 36, 1996, P. 308. Utton A.E. Op. Cit. pp. 635-639.

11. Makhkambaev S.D. Mezhdunarodno-pravovoe regulirovanie sotrudnichestva gosudarstv po ispol'zovaniyu transgranichnykh vodnykh resursov v regione Tsentral'noi Azii: Diss. ... kand. yurid. nauk. M., 2011. S. 20. 
12. Sokolova N.A. Teoreticheskie problemy mezhdunarodnogo prava okruzhayushchei sredy. Monografiya / Otv. red.: Bekyashev K.A. - Irkutsk: Izd-vo Irkut. un-ta, 2002. S. 152. Timoshenko A.S. Formirovanie i razvitie mezhdunarodnogo prava okruzhayushchei sredy / Otv. red.: Kolbasov O.S. - M.: Nauka, 1986. S. 50-72. Nafziger J. Basic Functions and Principles of International Environmental Law in the Context of Managing Water Resources // Denver Journal of International Law and Policy Vol. 39 No. 3, 2011, pp. 381-395.

13. Caponera D.A. Patterns of Cooperation in International Water Law: Principles and Institutions. P. 570.

14. Birnie P., Boyle A. International Law and the Environment (second edition). Oxford University Press, 2002. P. 120.

15. Okowa Ph. Procedural Obligations in International Environmental Agreements // British Yearbook of International Law, 1996, P. 275-279 